\title{
HIGIENE E INFÂNCIA NO PARANÁ: A MISSÃO DE FORMAR HÁBITOS SAUDÁVEIS (1931-1949)
}

\author{
Liliana Müller Laroccaํ, Vera Regina Beltrão Marques²
}

\footnotetext{
${ }^{1}$ Doutora em Educação. Professora do Departamento de Enfermagem da Universidade Federal do Paraná (UFPR). Paraná, Brasil. E-mail: larocca_m@terra.com.br

${ }^{2}$ Doutora em História Social. Professora do Programa de Pós-Graduação em Educação da UFPR. Paraná, Brasil. E-mail: verarbm@terra.com.br
}

RESUMO: Com base na investigação dos discursos médicos referentes à higienização da infância, este estudo teve por objetivo problematizar a difusão da higiene na sociedade paranaense no período compreendido entre 1931 e 1949. Trata-se de uma pesquisa de caráter histórico, inspirada nas ideias de processo civilizador de Norbert Elias. Os discursos que evidenciavam a missão de criar na infância local uma consciência sanitária com vistas ao progresso e a inserção do Paraná no cenário político nacional foram resgatados na Revista Médica do Paraná. Emergiram percepções de uma medicina com uma nova função social: educar e civilizar a infância, utilizando para tanto a estratégia da higienização.

DESCRITORES: Higiene. Ciência. Educação. Cuidado infantil.

\section{HYGIENE AND INFANCY IN PARANÁ, BRAZIL: THE MISSION TO DEVELOP HEALTHY HABITS (1931-1949)}

\begin{abstract}
Based on investigating medical accounts referring to childhood hygiene, this study aimed to discuss the diffusion of hygienic practices in the Paraná state society between 1931 and 1949. It is a historic study in nature, inspired by Norbert Elias's ideas on the civilizing process. The accounts, which evidenced the mission of bringing about hygiene awareness among local children with aims to foster progress and insert the state of Paraná, Brazil, in the national political scenario, were extracted from the Paraná State Medical Journal (Revista Médica do Paraná). Perceptions emerged concerning medicine with a new social function: to educate and civilize infancy through utilizing a hygiene strategy.
\end{abstract}

DESCRIPTORS: Hygiene. Science. Education. Childhood care.

\section{HIGIENE E INFANCIA EN PARANÁ, BRASIL: LA MISIÓN DE FORMAR HÁBITOS SALUDABLES (1931-1949)}

\begin{abstract}
RESUMEN: Teniendo como base la investigación de los discursos médicos referentes a la higienización de la infancia, este estudio intenta problematizar la difusión de la Higiene en la sociedad paranaense durante el período comprendido entre 1931 y 1949 . Se trata de un estudio de carácter histórico, inspirado en las ideas del proceso civilizador de Norbert Elias. Los discursos que evidenciaban la misión de crear en la infancia local una conciencia sanitaria con vistas al progreso y la inserción del Paraná, Brasil, en el escenario político nacional fueron investigados en la Revista Médica del Paraná. Surgieron percepciones de una medicina con una nueva función social: educar y civilizar a la infancia, utilizando para ello la estrategia de la higienización.
\end{abstract}

DESCRITORES: Higiene. Ciencia. Educación. Cuidado infantil. 


\section{INTRODUÇÃO}

No Brasil, em meados do século XX, um fluxo de transformações atingiu vários níveis das relações sociais. Foram mudanças impactantes estimuladas, principalmente, por um novo dinamismo no contexto da economia internacional, as quais alteraram a ordem e as hierarquias sociais, as noções de espaço e tempo dos indivíduos e os modos de percepção do cotidiano. ${ }^{1}$ As pessoas foram envolvidas num intenso processo de transformações de hábitos, convicções e percepções. Considerada por muitos uma "religião", a higiene e seus preceitos despertaram nos médicos paranaenses uma missão educativa e de transformação social. A ideia de progresso, contida na nova "missão", valorizava a capacidade do ser humano usar a razão para assumir a direção de sua vida social com impacto na marcha nacional rumo a um futuro grandioso. Se atualmente se apresentam como noções aparentemente vagas, à época estudada se depararam aos brasileiros sob a forma de prescrições e estratégias bastante claras: higienização e educação.

A medicina legitimara-se por meio de novos conhecimentos científicos, que conferiram aos discursos médicos diferentes bases de fundamentação. Caracterizada como profissão que vislumbrava os problemas encontrados na vida cotidiana, para além do corpo doente, a ciência médica os considerou passíveis de reinterpretação e alcançou maior poder na sociedade, logrando atingir o processo reconhecido como medicalização. ${ }^{2}$

O progresso das sociedades humanas implicou dimensões não redutíveis apenas ao progresso técnico-científico, de modo que foram também englobadas as questões morais. Os médicos, como intelectuais, autodelegaram-se a missão de higienizar a sociedade mais particularmente à infância. Ao se apresentarem como promotores de uma possível ruptura com o passado colonial, operaram um ideário de construção de novos cidadãos: higienizados, modernos e civilizados.

O objetivo deste estudo foi reconhecer as prescrições higienistas para a infância paranaense, na perspectiva civilizatória, contidas nos discursos médicos publicados na Revista Médica do Paraná, no período compreendido entre os anos de 1931 e 1949.

Ao optarmos pelo entrelaçamento higieneeducação no discurso médico paranaense, refletimos sobre a necessidade de perceber os processos de produção e representação dessas dimensões como ferramentas civilizatórias.
Consideramos os discursos médicos como práticas sociais, o que significou compreendê-los como construção social e coletiva. Foram analisados sob um contexto histórico, cujos enunciados representam visões de mundo determinadas e necessariamente vinculadas à sociedade em que viveram seus autores. ${ }^{3}$

Nos seus estudos, Elias ${ }^{6-8}$ apresentou vários sentidos do conceito de civilização, destacando: uma identidade particular dos sistemas filosóficos e dos povos; o acréscimo de mudanças no comportamento e na aparência externa de seres humanos; a disputa entre a classe burguesa europeia e a sociedade da Corte; a oposição entre a suavidade das maneiras e a urbanidade e o aprimoramento das instituições educacionais e legais por meio do aumento de conhecimentos. Para o autor, civilidade seria um modo de vida que pretendia opor-se a outro. No caso paranaense, tomamo-la como a construção de um modo de vida que se oporia ao arcaico, pois a sujeira, a pobreza, a miséria, a degenerescência da raça, as moléstias, a proximidade e o compartilhamento de espaços tão usuais nas cidades tornaram urgente a determinação de regras de conduta.

\section{METODOLOGIA}

Neste estudo, as prescrições médicas para a infância foram o foco investigativo, como legado de conhecimento cultural. A ideia de cultura implica "[...] a ideia de tradição, de certos tipos de conhecimentos e habilidades legados por uma geração para a seguinte [...]". 4:39 Algumas das transformações pretendidas pelos intelectuais médicos ocorreram por conta, inclusive, de embates frente às resistências exercidas pelos sujeitos e segmentos sociais afetados pela ação médica, o que produziu, entre outras estratégias, práticas de cunho educativo que concorreram para a formação dos indivíduos. ${ }^{5}$

Trata-se de uma pesquisa histórica, na qual a dimensão está estruturada na História Cultural, com inspiração nos conceitos desenvolvidos por Norbert Elias, tendo uma abordagem nos discursos produzidos na Revista Médica do Paraná, entre os anos de 1931-1949, e um domínio na história da higiene produzida pelos médicos paranaenses. A Revista Médica do Paraná foi órgão de divulgação da Sociedade Médica dos Hospitaes do Paraná (fundada em dezembro de 1930), cujo começo remonta dezembro de 1931, mantém sua periodicidade até os dias atuais, agora sob a chancela da Associação Médica do Paraná. 
As fontes consultadas, num total de 25 volumes analisados, pertencem ao acervo histórico da Biblioteca do Setor de Ciências da Saúde da Universidade Federal do Paraná, com complementação nos arquivos da Associação Médica do Paraná.

Como o período estudado representa tempos de intenso debate acerca de uma identidade nacional para o Brasil e seus estados membros, as obras de Norbert Elias ${ }^{6-8}$ foram importantes para pensar a construção das relações que permeiam o processo de civilização, individuação e a formação do Estado Nacional.

\section{RESULTADOS E DISCUSSÃO}

Muitos artigos publicados na Revista Médica do Paraná diziam respeito à relação saúdeinfância-escola, permeados por estratégias higienistas apresentadas pelos médicos paranaenses. Em número de lançamento, um artigo intitulado Verminose no meio escolar, ${ }^{9}$ destacava a importância de tornar a escola um ambiente acolhedor ao aluno, bem como campo de recomendações higiênicas impactantes na vida desses pequenos paranaenses. A pretexto da profilaxia da verminose, buscava criar um caso concreto de higiene capaz de provocar o interesse do aluno primário para certas práticas elementares de higiene individual que conteriam a base de defesa contra a maioria das doenças e não cansariam a criança com recomendações que pouco lhe diziam. A formação de uma consciência sanitária na infância contava com apoio da Inspeção Médica Escolar. Um dos objetivos dos médicos paranaenses era, ao atrair as crianças, provocar uma verdadeira revolução higienista na população: “[...] A criança não é um peso morto que quase toda a gente supõe. A criança é uma atividade exuberante capaz de exercer na ordem social um papel de alta valia construtiva, uma vez envolvida num interesse que não contrarie a expansão natural de sua energia. Ao educando compete não desperdiçar essa fonte perene de energias obediente às incitações para um fim útil, desde que não lhe faltem com a consideração e com o carinho que são condições essenciais para o desenvolvimento da estima de si mesmo, da honra e da liberdade, em suma, da confiança nos próprios esforços" . 9:107

Em tom missionário, o médico Jose Pereira de Macedo dizia: “ [...] assim praticando a Inspeção Medica Escolar vai, na medida do possível, classe por classe, em todos os nossos estabelecimentos de ensino primário aliciando a legião infantil para a grande campanha sanitária de cuja vitória depende, indiscutivelmente a própria vida da nação". 9:108

A fim de formar uma consciência sanitária, objetivo dos higienistas desde os anos de 1910, os médicos paranaenses destacavam que de nada valiam compulsões, leis, regulamentos e multas se os indivíduos não compreendessem o verdadeiro objetivo das medidas adotadas. Entender porque era importante adquirir hábitos saudáveis é que levaria à compreensão de que as normatizações higiênicas "não seriam abusos dos mandatários". 9:108

Resolver a questão educacional sob o ponto de vista médico-higênico era, para muitos, o grande desafio da medicina brasileira e paranaense: “[...] desde a mais tenra idade deve-se procurar incutir no individuo hábitos sadios para que a hygiene não lhe appareça como um corpo de prescrições e de noções ou como algum ritual enxertado em seus habitos espontaneos, mas ao contrario deva naturalmente fazer parte de seus costumes e insinuar-se sem esforço voluntario nos actos de sua vida diária" ${ }^{10: 154}$

Os princípios da educação sanitária, os quais seriam capazes de transformar os imprescindíveis hábitos higiênicos em uma segunda natureza para a infância, foram apresentados: “[...] aproveitar a idade infantil para introduzir no indivíduo hábitos que automaticamente passem a fazer parte de sua personalidade; A educação sanitaria tem que ser essencialmente praticada e exercitada num meio perfeitamente hygienizado; Deve-se procurar pelo exemplo conduzir a creança á imitação de maneiras salutares até que subrepticimente ellas se casem aos seus hábitos; E' pela lei do hábito, que é a Lei fundamental da Biologia, segundo Lamarck, que chegaremos à plena consecução desta finalidade educativa; A escola é o meio propicio para esta educação não só porque as crianças facilmente se deixam modelar á vontade dos professores mas tambem por se tornar o centro de irradiação de conhecimentos que se quer generalisar; [...] A Hygiene - filha mais moça da Medicina se apresta cada vez mais para esta lucta titânica, mas só attingirá á Victoria si cada um de nós levar á sua obra um contingente de utilidade e efficacia, auxilio com que só poderá contar quando todos nós possuirmos a verdadeira consciencia sanitária $[\ldots]^{\prime \prime}{ }^{10: 154-6 .}$

Não por coincidência, o ideal eugênico era lugar comum nos discursos higienistas. Os tão alarmantes "flagellos nacionais" nominados por Belisário Penna e outros na década de 1920, continuavam sendo constantes e o conhecimento 
científico da época imputava à eugenização a possibilidade de solução de grande parte da problemática. Evitar o nascimento dos débeis, tarados e doentes, bem como o desafio de seu cuidado, foi palco de discursos e prescrições desde o início do século XX, intensificando-se no Paraná entre os anos de 1930 e 1940.

A investigação pormenorizada da criança - corpo, família, escola - era inviável com o numerário médico local. Então, essa missão precisava ser em parte delegada àquelas pessoas que tinham contato diário com os futuros cidadãos paranaense - as professoras. Em 1933, o médico paranaense Mario Gomes publicou uma série de três artigos encomendados pela Revista Medica do Paraná, assim intitulados: Ensaios de puericultura: cuidados especiais com prematuros, débeis, tarados e doentes; Período escolar e puberdade; e Adolescência e Juventude, ressaltando: “[...] o desenvolvimento infantil prossegue intensamente até á puberdade e ainda depois, até aos 20, 25 anos, desde que se cultivem as qualidades físicas pelos desportos e as intelectuais e morais pelo estudo e aperfeiçoamento moral. E assim os pais - particularmente as mães - que assistem desde o berço até á idade madura esse incessante crescimento, essa maravilhosa transformação porque passa o entezinho, inconsciente ao nascer, até o individuo complexo que representa o homem culto ou a mulher educada - nenhum esforço pouparão para gerá-los e criá-los perfeitos". 11:101

A delegação de algumas responsabilidades às professoras, sempre com supervisão médica, apareceu nas discussões relativas ao papel de educar para a formação de hábitos saudáveis, bem como o dever moral do professorado em praticar e estimular a higiene: "[...] como entender o que se chama educação? Educação é a ação exercida junto ás crianças pelos pais, e depois pelos mestres, com o objetivo de iniciá-las na prática dos deveres morais. Em que consistem esses deveres? Compreendem os deveres para com a própria pessoa: cuidados higiênicos, bons hábitos, que formam o caráter pessoal $[\ldots . .]^{\prime \prime} .{ }^{11: 118}$

O papel feminino foi destaque nos artigos: "[...] à mulher incumbia a sublime tarefa de ser a primeira educadora dos filhos, pois era fonte da família e da humanidade. Não deveria perder o ensejo de convencê-los de que não tem mérito neste mundo quem não é útil; e que somente pela aplicação, trabalho e esforço é que se consegue ser útil". 11:114 Esse conhecimento seria gradualmente transmitido, entremeado de jogos e brincos, em geral praticados nas chamadas escolas maternais ou jardins de infância, onde deveriam ser aplicados todos os preceitos conhecidos e recomendados pela higiene escolar: local seco, solo poroso, presença de gramados e arvoredo, salas arejadas, paredes decoradas com motivos apropriados à idade juvenil, móveis proporcionais à idade e estatura das crianças, salas para vestiário e repouso, lavabos e instalações sanitárias especiais, tudo isso sob a direção "carinhosa de mestra, com auxiliares possuindo vocação e curso especializado para esse mister". ${ }^{11: 120}$

A admissão dos alunos no jardim de infância deveria acontecer sob rigorosa seleção médicopedagógica "não se admitindo, desde as que não ofereçam indispensáveis condições de trato e asseio, até as portadoras de pediculose, escabiose, moléstias de pele e dos olhos, suspeitas de tuberculose e outras doenças transmissíveis [...]". 11:120

O exame médico deveria, pelos princípios higiênicos adotados, ser extensivo às professoras e serventuários da Escola "[...] não se admitindo os que possam ser portadores de molestias contagiosas, especialmente a tuberculose". 11:120

Para os médicos paranaenses, "a verdadeira idade escolar" estava compreendida entre os seis ou sete anos até os 12 ou 13 anos. Nessa fase da vida, as crianças já teriam atingido grau de desenvolvimento intelectual, principalmente as que haviam frequentado o jardim da infância ou escola maternal. O desenvolvimento necessário à boa formação poderia ser adquirido por meio da lição de coisas e de conhecimentos elementares, bem como pela aquisição de hábitos disciplinares. A somatória desses fatores permitiria o aparecimento de sentimentos de natureza elevada "a ponto de a criança ser capaz de estudar com prazer, considerando mesmo a instrução como algo útil. Esse crescente amor ao estudo, mais comum nas meninas do que nos meninos, acentua-se nos mais inteligentes ou nos bem educados". ${ }^{11: 121-2}$ Além disso, os ensinamentos recebidos nos primórdios da idade infantil, com destaque para os recebidos pela mãe e primeira mestra, poderiam ser os propulsores de uma "boa educação para o bem". 10:122 Assim, os educadores (professores e médicos) seriam aqueles "que tudo precisam conhecer para prover e fiscalizar [...] as condições do terreno em que vai se erigir o prédio escolar, sua construção, conservação e limpeza, até os cuidados individuais dos escolares [...] asseio da cabeça, do corpo e das vestes; conservação dos dentes; atitude nas classes e fora delas; pratica regular e metódica dos exercícios físicos e da alimentação." ${ }^{11: 122}$ 
A conservação e manutenção das condições higiênicas das escolas caberiam ao professor que, com a máxima vontade, deveria atenuar os prejuízos do cerceamento à liberdade infantil: “[...] É na escola que a criança passa longas horas, contrariando sua disposição natural, que é pela liberdade, no campo, nos prados ou jardins. Dessa coação necessária aos fins do ensino, resultam certos prejuízos que o educador deve atenuar [...] Haverá o cuidado de renovar frequentemente o ar das salas, conservando as janelas abertas pelo tempo quente [...] ou pelo mau tempo. Por vezes será necessário provocar correntes para a renovação de ar das classes, abrindo uma porta e janela opostas e resguardando os alunos num canto da sala, onde poderão executar alguns números de ginástica fisiológica, enquanto aguardam a renovação". 11:123

Recreio e exercício físico também eram alvo dos higienistas e seus colaboradores: "[...] o pátio de recreio, seco e arenoso, alem do bom estado de conservação, será arborizado, porem de modo a não prejudicar a boa iluminação das salas de aula. Haverá também um pavilhão protegido para os dias chuvosos e para os exercícios físicos. Os exercícios visarão o desenvolvimento harmônico de todos os órgãos e não o preparo de atletas [...]". 11:123

No que concerne aos tipos de jogos e competições, preconizava a proibição, antes da adolescência, de jogos violentos "[...] como o football, nem mesmo competições de corridas a pé, ou de bicicleta". ${ }^{11: 123}$

A alimentação consistia capítulo à parte nos artigos pesquisados, medições e composição alimentar eram amplamente prescritas: “[...] Quanto á alimentação, durante o período escolar, o mestre por ela deve mostrar o máximo interesse, quer nas cantinas escolares, quando as houver [...]". 11:123-4

O desenvolvimento e a defesa da saúde infantil dependiam, além das ações dos professores, de uma complementaridade da ação médica: " [...] O médico-escolar começará examinando detidamente todos os candidatos á matricula nos cursos escolares - pois os atestados exigidos não representam suficiente garantia; - assim serão afastados os portadores de moléstias infecto-contagiosas e os anormais. Esse exame será repetido duas vezes por ano e completado pelos exames de acuidade visual e auditiva, sendo tudo isso registrado na ficha sanitária escolar $[\ldots . .]^{\prime \prime} .{ }^{11: 124}$

A escola foi, no período do estudo, exaltada como locus privilegiado e de alto alcance moral no preparo adequado do cidadão à vida social. A educação, num tripé - físico, instrutivo e moral seria capaz de formar o cidadão "[...] ente forte e robusto habituado á atenção, reflexão e força de vontade." 11:124

Ao final da década de 1930, a palavra eugenia cedeu gradativamente lugar em artigos e discursos dos médicos paranaenses ao termo genética, mas não prescindiu dos ideais eugênicos. Como ciência experimental, a psicologia e sua relação com o desenvolvimento infantil e a compreensão da conduta humana foram apresentadas pelo médico paranaense Pereira de Macedo, em artigo intitulado A psicologia genética na educação: “[...] A compreensão da conduta humana depende do conhecimento das reações dos indivíduos e, assim, a psicologia descendo das abstrações puramente filosóficas para o domínio da ciência experimental, revestiu-se de um caráter de verdade cientifica que a ninguém é dado recusar [...] Se a criança se engana, deixai fazer, não corrigi seus erros [...] Se ela não errasse não aprenderia tão bem" ${ }^{12: 90-1}$

Ao abordar aspectos relativos à civilização, afirmou: "[...] Assim como o selvagem obedece ás ações ativas e reativas de sua própria psicologia, a conduta do homem civilizado não pode fugir ás mesmas leis psicológicas das suas necessidades presentes, determinada por uma mentalidade bem diversa [...] Submeter o selvagem á lógica do civilizado é um contracenso tão grande como o de impor á criança a lógica do adulto. A criança não é um adulto em miniatura como se supunha até ha bem pouco tempo [...] mas um ser distinto que tem necessidades próprias e uma mentalidade adaptada a estas necessidades [...] para ser um bom civilizado é preciso ter sido, como criança, um bom selvagem". ${ }^{12: 93-6}$

Alguns autores da fonte pesquisada defendiam a existência de quatro tipos de crianças: sensorial, imitativo, intuitivo e racional. Estes tipos corresponderiam às fases da evolução infantil, sendo base para a organização das prescrições médicas, formadora de hábitos saudáveis e, consequentemente, de cidadãos contribuintes, com esforço e trabalho para o progresso paranaense. Conforme as fases deveriam variar também os processos educativos: "[...] Ao tipo sensorial recomenda-se ensino empírico, concreto e manual. Ao tipo imitativo ou na idade em que predomina o espírito de imitação, tarefas claramente fixadas, utilização da memória. Ao tipo intuitivo ou da idade que caracteriza a fase individualista, deixar uma grande parte à iniciativa individual e à imaginação. Enfim, reservar o estudo racional e lógico, ao tipo e 
á idade a que convém esta modalidade de ensino da qual se abusa demasiado hoje em dia"..$^{12: 105}$

A importância dos primeiros anos da infância na formação do adulto eram frequentemente ressaltadas " [...] a integridade psíquica e física depende, em grande parte das condições favoráveis ao desenvolvimento infantil no que respeita ás suas tendências primitivas, ás suas necessidades e aos seus interesses subordinados ao tipo psicologico e á fase de evolução". ${ }^{12: 105-6}$

A publicação da Revista Médica do Paraná, reconhecida neste estudo como importante veículo difusor do ideal higienista no estado, trouxe em seu quinto ano de publicação ininterrupta artigos que continuavam a destacar o papel missionário dos médicos e a importância da prescrição de "práticas civilizadoras" junto à infância paranaense. Olhar e antever um futuro era também perceber o progresso, e com ele seus problemas, entre os quais o mais destacado foi a criminalidade. $O$ preço do progresso e da civilização sem a devida medicalização da sociedade era apontado pelos editores do periódico: "[...] chegue o Paraná a um grau de civilização e de riqueza muito alto, tenha ele se desenvolvido quanto merece e observaremos, por certo, que, ao lado deste vosso progresso, vós tereis paralelamente $\mathrm{o}$ argumento da criminalidade. $\mathrm{O}$ criminoso acompanhará o vosso progresso, ele se abrigará debaixo da vossa honestidade, para se aproveitar daquilo que vós conseguireis com o vosso esforço $[\ldots]^{\prime \prime} .^{13: 51}$

O alvo de intervenção conjunta entre criminologistas e o higienista seria a criança: "[...] há indivíduos, por exemplo, que já nascem rebeldes aos pais, há filhos que já nascem 'respondões'. Eles assim o são porque alguma coisa os faz assim o ser. E' preciso que se os estude sob o ponto de vista médico-psicológico, que se os corrija sob este ponto de vista, que se investiguem as suas tendências: assim se fará em suma a profilaxia [...] Não ha crimes e doenças, mas sim, criminosos e doentes."13:59-60

A conquista de hábitos saudáveis, por meio da educação higiênica e da disseminação das prescrições médico-higiênicas, precisava de novas armas. Em 1937, no Paraná, o rádio se apresentou como auxiliar da cruzada higienista. A Revista Médica do Paraná reproduziu, no sexto ano de publicação, programas da Rádio Clube Paranaense (PRB-2) sobre higiene doméstica. O primeiro deles, realizado pelo médico paranaense Dirceu de Lacerda, preconizava: "[...] Minha Senhora. Boa Noite! A nossa presença ao microphone representa a soli- dariedade da classe medica á grande iniciativa da Saúde Pública - educar o povo, através das ondas desta escola de cultura, que á a PRB-2."14:347-52

Em 1941, o médico paranaense Glaucio Bandeira apresentou na seção "Nosso comentário" considerações sobre a saúde escolar: "[...] Nunca será demais repetir e insistir que um dos assuntos magnos na civilização é a educação da criança. Repositório das mais ouças e rutilantes esperanças, vanguardeira do porvir com toda messe de realizações futuras, tem merecido a infância - os mais dedicados esforços dos educadores e médicos no intuito de proteção para um desenvolvimento sadio à altura de empreendimento a que está destinada." $15: 35$

A formação de um biotipo padrão para a infância brasileira (baseada em dados internacionais) foi apresentada como imprescindível para divulgar preceitos higiênicos e educacionais, e assim evitar a anormalidade: "[...] nem todos os escolares são iguais, quer sob o ponto de vista intelectual, quer sob o ponto de vista físico e quer como expressão genérica do tipo social hígido. Há os normais, e os anormais, como sabeis, dividem-se em vários grupos: há os anormais sensoriais e que precisam fazer a educação em estabelecimentos especiais. Há, ainda, os anormais psíquicos, de que a Pedagogia não se preocupa jamais. Há, ainda, os anormais físicos. Há os anormais suscetíveis de educação, que são os que interessam aos educadores: são os insuficientes, sob o ponto de vista intelectual e os viciados. Estes são os que mais constantemente conclamam médicos e educadores para a obra altamente patriótica de transformar um ser que, deixado à sua sorte, será levado ao cárcere ou ao manicômio. Amparado pelas duas forças conjugadas - Medicina e Pedagogia, transformar-se-á em fator útil a si, à sociedade e à Pátria. Há, enfim, outros pequenos anormais que ficam nas classes comuns [...] que podem trabalhar e progredir ao lado de outros escolares, são os pequenos doentes, os nevropatas, psicastênicos, distônicos, linfáticos [...]." ${ }^{15: 41}$

A necessidade da experimentação de dificuldades por parte das crianças foi destacada como forma de aprendizado utilizando-se para tal das lições da experiência: "[...] instruir é ensinar arte de transpor o espaço sideral, é ensinar a intransigência pelos ideais e a compaixão pelos homens; é ensinar ponderação e equilíbrio; é reconhecer com desprezo o que é vil e desenvolver o sentimento do belo; é ensinar que na dor revelamos a medida do nosso valor moral; é aprender a viver; é saber morrer; é enfim amar a Deus e aos homens."154:42 
Aos alunos das escolas paranaenses fazia-se o seguinte apelo: "[...] colaborar ativamente na obra sacrosanta e patriótica de bem servir nossa extremecida Pátria pela sua redenção no domínio da ciência pura e desinteressada, da elevação cultural, profissional e técnica." 15:42-3

Paulatinamente as referências à Higiene, Educação Sanitária e Saúde Escolar foram substituídas, na Revista Médica do Paraná, por temas mais voltados à descrição de agravos e novas terapêuticas. Entretanto, os ideais higiênicos continuaram. Afinal, foram décadas de propagação de discursos. Quase meio século XX já havia transcorrido e permanecia divulgada na Revista Medica do Paraná a parceria entre higienistas e educadores.

Chegaram os anos de 1950 e a formação da infância paranaense, mesmo sem prescindir da higiene, educação e eugenia, clamava pela assistência à saúde e pelo desenvolvimento de especialidades médicas voltadas ao atendimento das necessidades biológicas da população. Estavam na pauta do dia: a organização dos serviços, a descentralização das ações e a criação de um órgão normativo único - o Ministério da Saúde.

\section{CONSIDERAÇÕES FINAIS}

Em meados do século XX, o ideal de progresso adquiriu para os médicos paranaenses significados que possuíam um mesmo receituário a balizar seus discursos: higiene se ensina na infância e se aprende na escola.

Nos anos de 1930 e 1940 a organização de uma ordem médica no Paraná, centrada em um modelo projetado com bases na racionalidade científica advinda da higiene, produziu mais que discursos; passou a elaborar prescrições para a infância.

Cuidar, proteger e higienizar a infância, foi tarefa assumida pelos médicos paranaenses, com vistas à inserção de nosso território no processo de saneamento sanitário e social que, uma vez disseminado, promoveria a melhoria de nossa gente, de nossa raça e a contenção das doenças que nos assolavam.

Tratamos neste estudo de discursos médicos que podem ser considerados, ao mesmo tempo, objetos e fontes, os quais no Paraná produziram representações singulares acerca da infância, que uma vez saneada e medicalizada, seria capaz de construir o caminho do progresso. ${ }^{16}$

Nossa pretensão foi dar visibilidade à missão de civilizar a infância paranaense por meio de sua higienização, intervindo no cotidiano infantil de forma a torná-lo civilizado. E assim caminho para o progresso e redenção nacional, valorizando a higiene como estratégia.

Mesmo uma pesquisa sendo interminável, um texto "deve ter um fim" cuja introdução já deve ser organizada pelo "dever de terminar". Certamente, lacunas ficaram expostas pelo caminho, mas o caminhar acabou se transformando no maior desafio empreendido. ${ }^{17}$

Saberes médicos voltados para a infância foram construídos e se aproximaram dos saberes pedagógicos, expondo frequentemente aspectos contraditórios, mas que tiveram como base a higienização dos pequenos. Esta produção de saberes e prescrições já foi comparada a um caleidoscópio, cuja visão infinita permite desvelar relações entre sujeitos higienizadores e higienizados e a produção de procedimentos de controle e dependência. ${ }^{18}$

Os discursos produzidos pelos médicos paranaenses para a infância foram vasculhados de modo a romper uma possível linearidade da escrita. Assim, estabelecemos conexões entre as fontes evitando reconhecê-las como documentos, que refletem apenas um lugar, tempo ou cultura unificados. ${ }^{5}$ Fontes não têm sentido por si e os discursos produzidos refletem os movimentos possíveis de visibilidade no momento em que foram investigados. Muitas tramas dessa ampla "teia", porém, ainda estão invisíveis.

Apostamos neste estudo, nas propostas de civilidade contidas nos discursos médicos, elaborados para a infância paranaense. A higiene nos serviu como fio condutor, em especial a partir das análises de Norbert Elias, cujo arcabouço teórico foi fundamental na construção da narrativa ora apresentada.

Nas primeiras décadas do século XX, os resultados da intitulada Revolução CientíficoTecnológica mundial envolveram alguns intelectuais brasileiros que estimularam sobremaneira a organização do espaço urbano na adesão ao conceito de modernidade, o que acabou por acelerar processos de desenvolvimento nas áreas da saúde e educação ancorados na Higiene. ${ }^{19}$

Examinar a relação entre o discurso médicohigienista e a civilidade republicana materializada nas fontes pesquisadas possibilitou compreender o trinômio higiene/civilidade/infância contido nos discursos sobre representações da saúde, entendida como capaz de redimir a nação e regenerar a população. 


\section{REFERÊNCIAS}

1. Sevcenko N. O prelúdio republicano, astúcias da ordem e ilusões do progresso. In: Novais F, organizador. História da vida privada no BrasilRepública: da Belle Époque à Era do rádio. São Paulo (SP): Cia das Letras; 1998. p.7-48.

2. Dupas G. O mito do progresso. São Paulo (SP): Unesp; 2006.

3. Iñiguez L. Manual de análise do discurso em ciências sociais. 2a ed. Petrópolis (RJ): Vozes; 2005.

4. Burke P. O que é história cultural? Rio de Janeiro (RJ): Zahar; 2005.

5. Stephanou M. Governar ensinando a governar-se: discurso médico e educação. In: Faria Filho M, organizador. Pesquisa em história da educação: perspectivas de análise, objetos e fontes. Belo Horizonte (MG): H.G. Edições; 1999. p.153-68.

6. Elias N. O processo civilizador - formação do estado e civilização. v.2. Rio de Janeiro (RJ): Zahar; 1993.

7. Elias N. O processo civilizador - uma história dos costumes. v.1. Rio de Janeiro (RJ): Zahar; 1994.

8. Elias N. Os alemães - a luta pelo poder e a evolução dos habitus nos séculos XIX e XX. Rio de Janeiro (RJ): Zahar; 1997.

9. Macedo JP. Verminose no meio escolar. Rev Médica do Paraná. 1931 Dez; 1(1):107-9.
10. Munhoz MM. Consciência sanitária. Rev Médica do Paraná. 1932 Mar; 1(4):151-6.

11. Gomes M. Ensaios de puericultura. Rev Médica do Paraná. 1933 Abr-Mai; 2(5):101-24.

12. Macedo JP. O médico nas escolas. Rev Médica do Paraná. 1934 Mar; 3(3):85-106.

13. Carvalho HV. Conferência. Rev Médica do Paraná. 1936 Fev-Mar; 5(2/3):51-60.

14. Lacerda D. Palestra. Rev Médica do Paraná. 1937 Set; 5(9)347-52.

15. Bandeira G. Nosso comentário. Rev Médica do Paraná. 1941 Jan; 10(1):35-43.

16. Gondra JG. Artes de civilizar: medicina, higiene e educação escolar na corte imperial [tese]. São Paulo (SP): Universidade de São Paulo; 2000.

17. Certeau M. A escrita da história. $2^{\mathrm{a}}$ ed. Rio de Janeiro (RJ): Forense Universitária; 2000.

18. Stephanou M. Tratar e educar: discursos médicos nas primeiras décadas do século XX [tese]. Porto Alegre (RS): Universidade Federal do Rio Grande do Sul. Programa de Pós-Graduação em Educação; 1999.

19. Mecone MCC, Freitas GF. Representações da enfermagem na imprensa da Cruz Vermelha Brasileira (1942-1945). Texto Contexto Enferm. 2009 Out-Dez; 18(4):741-9. 